March 2001

\title{
Ideology, Human Capital, and Growth
}

\author{
Murat F. Iyigun \\ University of Colorado, Boulder \\ murat.iyigun@stripe.color ado.edu \\ H. Naci Mocan \\ University of Colorado, Denver and NBER \\ nmocan@carbon.cudenver.edu
}

Ann L. Owen

Hamilton College

aowen@hamilton.edu

\begin{abstract}
We develop an endogenous growth model in which technological progress raises the efficiency of time allocated to education, and knowledge and ideology play complementary roles in determining individuals' efficiency units of labor input. A higher supply of aggregate units of efficiency labor generates incentives to invent new technologies because it raises the monopoly rents from the introduction of such technologies. We show that economies with initally more "fact-consistent" ideologies are likely to invest more in education and as a result experience faster technological progress and growth. Somewhat paradoxically, we also demonstrate that relatively more fact-consistent ideologies are the ones likely to experience weakening support. Adherence to flexible ideologies that evolve over time remains high even in the long run. When there exists a feedback loop between education and ideology, a flawed ideology may be better for growth and development than no ideology. Finally, the frequency with which ideologies are adopted and spread may be decreasing in the sophistication of technology.
\end{abstract}

Keywords: Technological Progress, Growth, Human Capital Accumulation, Ideology. JEL Classification Numbers: D80, J24, O33, O40.

Without implicating, we would like to thank David Bowman, Ann Carlos, Jon Faust, Herschel Grossman, Andrew Levin, and Omer Moav for useful comments and suggestions. Please send all correspondence to Murat Iyigun, University of Colorado at Boulder, Department of Economics, Campus Box 256, Boulder, CO 80309-0256. Phone: (303) 492-6653. Fax: (303) 492-8622. 
"There are no truths, only interpretations."

Frederich W. Nietzsche (1844 -1900).

\section{Introduction}

A salient feature of ideologies is that they help individuals make generalizations about the complex environment within which they operate and about which they have incomplete knowledge. ${ }^{1}$ Accordingly, ideologies not only influence how individuals interpret their experiences but they also complement the factual information they possess. Implicit in these assertions is the notion that ideologies may be economically useful. Indeed, the roots of the idea that ideologies help to serve an economic purpose can be traced back to Adam Smith who recognized one form of ideology, religion, as a rational means for individuals to enhance their human capital. ${ }^{2}$

The ideology and human capital interaction can also be found in Azzi and Ehrenberg (1975), Stark, Iannaccone and Finke (1996), and Iannaccone (1998), who contend that religion or involvement in religious activities should be treated by economists as a rational choice. Sacerdote and Glaeser (2001) present empirical support for the notion that religious beliefs and education are in fact substitutes. In a similar vein, Schumpeter (1949) comments on the role of ideology in the scientific process and discusses how ideology influences the search for "facts" in economics. In his address to the American Economic Association, he concludes:

"There is more comfort in the observation that no economic ideology lasts forever and that, with a likelihood that approaches certainty, we eventually grow out of each. This follows not only from the fact that social patterns change and that hence every economic ideology is bound to wither but also from the relation that ideology bears to that pre-scientific cognitive act which we have called vision. Since this act induces fact finding and analysis and since these tend to destroy whatever will not stand their tests, no economic

\footnotetext{
${ }^{1}$ North (1981, p. 49).

${ }^{2}$ See Anderson (1988) for a more thorough analysis of Adam Smith's discussion of religion in The Wealth of Nations.
} 
ideology could survive indefinitely even in a stationary world. As time wears on and these tests are being perfected, they do their work more quickly and more effectively. But this still leaves us with the result that some ideology will always be with us so, I feel convinced, it will. But this is no misfortune...[T]hough we proceed slowly because of our ideologies, we might not proceed at all without them."

In this paper, we incorporate ideology into an endogenous growth model. We present an overlapping generations model that examines how individuals make decisions when they have incomplete knowledge of the world. We develop the idea that individuals adopt ideologies to complement their formal learning in order to form working hypotheses about facts that their schooling does not fully explain. In other words, individuals adopt ideologies to help them conjecture about the way their world works when formal schooling exposes them only to a portion of this knowledge. The more ideologies accurately reveal what cannot be learned through schooling, the more "fact-consistent" they are. ${ }^{3}$ We embed this idea in an endogenous growth model and show how education and ideology interact to influence technological progress and growth.

This approach allows us to draw several interesting conclusions. First, we show how economies that initially have ideologies which are more consistent with reality are likely to accumulate more human capital (hereafter interchangeably referred to as knowledge), and consequently, experience faster technological progress and growth. Second, and somewhat paradoxically, we demonstrate that those economies that start out with relatively more fact-consistent ideologies are the ones likely to experience a weakening support for their ideologies. However, support for flexible ideologies that evolve over time remains high even in the long run. Third, the model highlights an important two-way interaction between education and ideology in which ideology affects the efficiency of education in learning facts about the world, and education affects ideological interpreta-

\footnotetext{
${ }^{3}$ Naturally, the meaning and purpose of ideologies can be interpreted in different ways. For instance, one can subscribe to the view that ideologies are non-deductive sets of beliefs about "right" and "wrong," and that they serve a more normative approach to life rather than provide a general framework with which to make judgements about how things work. In presenting the model below, we adopt the notion that such a framework forms the basis of making normative judgements. Put another way, we argue that while ideologies may help individuals form beliefs about what is "right" and what is "wrong," they do so within the context of some working hypotheses about their global environment.
} 
tions. In fact, it is this very interaction which primarily determines whether ideologies are flexible enough to survive in the long run. Fourth, based on the interaction between education and ideology, we also demonstrate that there exist circumstances in which a flawed ideology is better than no ideology. That is, even when an ideology is flawed such that schooling reveals more knowledge than what an ideology can offer when one subscribes to it, we find that it is possible for the stock of human capital to be higher compared to the case in which one does not subscribe to any ideology. ${ }^{4}$ And finally, our results suggest that technological advances will reduce the frequency with which new and widely-accepted ideologies emerge.

In what follows we describe a two period overlapping generations model where labor productivity and income depend on the efficiency of labor. Individuals have the option to subscribe to a prevailing ideology when young. Ideology supplements education by enabling individuals to develop a more comprehensive view of the world even when only incomplete knowledge is gained from education. Thus, if an ideology provides its adherents relatively more accurate conjectures about facts which were not learned through formal human capital investment, it can enhance their efficiency units of labor. Individuals choose to subscribe to an ideology if it increases their efficiency units of labor and, therefore, their consumption.

Because profits from invention are higher when workers are more productive, more fact-consistent ideologies will be associated with higher levels of human capital, higher rates of technological progress and faster growth. ${ }^{5}$ And since the level of technology is also a determinant of the efficiency of education in learning the true facts about the world, relatively more fact-consistent ideologies that initially generated higher levels of technology may become obsolete due to substitution between ideology and education. In other words, as technological progress makes education more efficient in learning

\footnotetext{
${ }^{4}$ One could argue that having no ideology is in fact an ideology. This point is semantic, however, as we could easily incorporate into our model an "ideology zero" which had no effect on human capital accumulation.

${ }^{5}$ Arguably, the evolution of ideologies themselves may have in fact shaped the institutional struct ure that accounts for how the monopoly rents from the discovery of new technologies accrued to their inventors, and that this interaction has been an important component of the development process. Although we take the security of property rights as given and assume that monopoly rents from the invention of new technologies were reaped by those who invented them, the results we present below would be further strengthened if we were to model the evolution of these institutional structures as endogenous to the choice of ideologies as well. We elaborate on this potential link in more detail below.
} 
about the world, an unchanging ideology may become less useful and can eventually be abandoned. Only when ideologies are flexible enough so that its adherents' ideological inferences respond to changes in prevailing scientific knowledge, do ideologies survive in the long run. In turn, it is these types of ideologies that inevitably lead to sustained technological progress.

While the prediction that inflexible ideologies could face a decline in the face of scientific and technological advances is not new-as their variants can be traced back to Hume (1911) and Comte (1855) who argued as such specifically with respect to religionsupportive empirical evidence has recently begun to emerge. For example, Sacerdote and Glaeser (2001) find that religious attendance rises sharply with education across individuals but that it declines strongly with education across denominations. They show that denominations are fundamentally defined by their religious doctrines and that the highly educated are likely to switch into "low belief" denominations.

Our paper is related to a number of others that have studied the determinants of economic growth and development in the very long run. ${ }^{6}$ As an endogenous growth model, our work can also be linked to others that have examined the relationship between incentives to innovate and the human capital stock. ${ }^{7}$ Our paper is distinct, however, because we highlight the effect of the cultural or ideological environment in this process. In our paper, ideology affects the efficiency of human capital accumulation which ultimately determines the incentive to innovate and the level of technology. At the same time, technology affects ideology through its impact on the efficiency of learning. Thus, there is an important feedback loop through which ideology, human capital accumulation and technological innovation interact.

Despite the fact that we do not explicitly model the interplay between individuals' ideological choices and the collective determination of institutional features, our model is also related to work on institutions and economic development. ${ }^{8}$ From an historical perspective, there appears little doubt that prevalent ideologies have influenced-for better or worse-the design and evolution of institutions relevant to commerce. Rosenberg

\footnotetext{
${ }^{6}$ See, for example, Galor and Weil (2000), Galor and Moav (1999, 2000a, 2000b), Jones (1999), and Kremer (1993).

${ }^{7}$ For example, Young $(1991,1993)$ and Acemoglu (1998).

${ }^{8}$ Fershtman and Weiss (1993), Knack and Keefer (1997), Hall and Jones (1999), Jones (1999) and Acemoglu et al. (2000).
} 
and Birdzell (1986) point out that the development of a moral system commensurate with wealth and capital accumulation can be traced back to the Calvinist Reformation of Protestantism in the 16th century, as "Calvin's doctrines of predestination and sanctification of work implied that capitalists might just as well keep their property in the family instead of donating it to the Church." They further note that the origins of this idea date back to Max Weber who credited the Calvinist Reformation for the subsequent rise of capitalism and the Industrial Revolution. ${ }^{9}$

The paper is structured as follows. Section 2 discusses and justifies the basic building blocks of our model. Section 3 sets up the basic model and describes the role and the determination of ideology. Section 4 considers the dynamic evolution of this economy. Section 5 discusses implications of the model, and Section 6 concludes.

\section{The Building Blocks}

Our model rests on the following key assumptions:

I) Both ideology and knowledge augment the efficiency of labor supply. The most direct empirical evidence was recently provided by Sacerdote and Glaeser (2001) who demonstrate the social networking aspect of religious attendance. They show that in denominations where beliefs are stronger (i.e., more orthodox ideologies) children are less likely to acquire formal human capital, suggesting that ideology and formal schooling are substitutes. ${ }^{10}$

While the fact that schooling allows individuals to gain knowledge is a standard assumption in the human capital literature, the idea that ideology also aids individuals in developing a framework for understanding the world is notably absent from formal economic models even though there exists a long history of philosophical and scientific thought on this issue. For example, Bacon and Hobbes, following Ockham, emphasized that scientific inquiry and piety, the claims of knowledge and those of belief should not interfere with one another. Leibniz went one step further and claimed the mutual support of reason and faith in the understanding of our environment. ${ }^{11}$ As noted earlier, Adam

\footnotetext{
${ }^{9}$ Weber (1930).

${ }^{10}$ As presented in Section 3.2, our results do not rely on perfect substitution between ideology and human capital.

${ }^{11}$ For more details, see Barnouw (1981) and Osler (1970). Also, many others have argued that religion and science play complementary roles in advancing knowledge. Both Newton and Einstein were religious
} 
Smith and, more recently, North (1981, p.47) have observed the usefulness of ideology in augmenting human capital. North articulates this particular feature of ideologies when he observes,

"Ideology is an economizing device by which individuals come to terms with their environment and are provided with a 'world view' so that the decision making process is simplified. [It] is inextricably linked with moral and ethical judgments about the fairness of the world the individual perceives. This situation clearly implies a notion of possible alternatives. Individuals alter their ideological perspectives when their experiences are inconsistent with their ideology. ${ }^{12}$ In effect, they attempt to develop a new set of rationalizations that are a better 'fit' with their experiences."

In this spirit, we do not assume that all ideologies have the same economic impact. We allow for some ideologies to be more fact-consistent and generate higher productivity. Of course, the interaction between ideology and human capital accumulation does not preclude ideology from having detrimental effects on labor productivity once human capital reaches a certain level.

men, and Einstein credited religion with a role in scienctific advancement when he said "Religion without science is blind. Science without religion is lame." [See Davies (1983).] Foster (1934) provides several examples of the influence of religion on science when he argues that belief in creationism actually allowed the birth of modern physics because it allowed scientists to abandon the Aristotilian methods that attempted to study nature by intuitive induction and to define its "essence." Foster argues that once scientists started with the presumption that nature was created by God, they adopted methods that allowed scientists to discern the properties of natural substances by observation and experimentation.

${ }^{12} \mathrm{An}$ example that perhaps best exemplifies such fact-inconsistent ideologies that were beneficial up to a point is the Quetzalcoatl myth. The patron of learning and magic for the Aztecs, Quetzalcoatl is believed to have represented the qualified unity of many pre-Columbian cultures and the continuity of their traditions. Thus, although adherence to this ideology facilitated the exploitation of the Aztecs by the Spanish explorer Cortes which eventually led to their downfall, belief in this ideology did initially help to create an advanced pre-Columbian civilization. [See Carlton (1977).]

Stephen (1876) gives examples of other ideologies that were adopted for their usefulness but are clearly fact-inconsistent today: Greek sailors gained an understanding of storms through their belief in the diety Proteus and ancient races adopted ideologies that assumed an order of nat ure and gave some understanding to the recurrence of times and seasons. Ancient believers in astrology also gained useful information for planting and harvesting as many constellations are associated with seasonal weather patterns.

A final example, to take a contemporary one, is communism. One could argue that adherents to this ideology adopted a view of the world that was useful in some context, but that the recent downfall of communism due, at least in part, to the stagnant or declining living standards proved this ideology to be fact-inconsistent as well. 
II) Education is more efficient when technology is more sophisticated. In our model the level of technology is a result of successful R\&D efforts and, therefore, is a proxy for the stock of scientific knowledge in the economy. ${ }^{13}$ When the stock of scientific knowledge is higher, schooling yields greater knowledge to the students. In other words, as technology advances education becomes more productive. This assumption is similar to one originally made by Romer (1990) in which the growth of human capital is increasing in the stock of human capital.

III) Knowledge may affect ideological interpretations. We allow individuals with different levels of knowledge but the same ideology to make different inferences about the world. This assumption closely matches the ideas in Schumpeter's 1949 address to the American Economic Association in which he describes a process where ideology inspires scientific investigation and higher levels of knowledge will lead to more accurate interpretation. Combined with the possibility that ideological beliefs may affect the human capital accumulation process, this generates a feedback loop between ideology and human capital. Although most of the results we present below are not predicated on this relationship, its existence leads to interesting dynamics in our model.

In the following two sections, we build these assumptions into an endogenous growth model and study their implications for growth in the standard of living as well as the long-term survival of ideologies.

\section{The Economy}

\subsection{Production}

Consider an economy in which real economic activity extends over an infinite discrete time. Production is carried out by a continuum of firms indexed by $j, j \in[0,1]$. In each period $t$, firms produce a single homogenous good, $y_{t}^{j}$, using a machinery aggregate, $M_{t}^{j}$, and a labor aggregate, $L_{t}^{j}$, with the following constant returns to scale production technology: ${ }^{14}$

\footnotetext{
${ }^{13}$ More accurately, higher levels of technology indicate that researchers have adapted current scientific knowledge into commercially viable products.

${ }^{14}$ We employ a specific Cobb-Douglas form for the determination of output because it helps to generate iso-elastic demand for machinery which in turn leads to constant monopoly markups and simplifies the analysis of technology adoption. Our qualitative results are not dependent on this specific functional form.
} 


$$
y_{t}^{j}=F\left(M_{t}^{j}, L_{t}^{j}\right)=\left(M_{t}^{j}\right)^{\alpha}\left(L_{t}^{j}\right)^{1-\alpha} ; \quad 0<\alpha<1 .
$$

The machinery aggregate, $M_{t}$, embodies the quantity as well as the quality (i.e., technological sophistication) of machines. ${ }^{15}$ By definition, aggregate output at time $t$, $Y_{t}$, equals $\int_{0}^{1} y_{t}^{j} d j$.

The labor market is competitive. Thus, the wage rate paid to labor, $w_{t}$, equals its marginal product:

$$
w_{t}=(1-\alpha)\left(\frac{M_{t}}{L_{t}}\right)^{\alpha}
$$

\subsection{Individuals}

Individuals, who are identical, live for two periods in overlapping generations. In the first period of life, they get educated, and in the second period, they work and consume. Preferences are represented by a utility function that is linear in consumption in the second period. ${ }^{16}$ There is no population growth.

Individuals have the option to subscribe to one ideology chosen from a set of available ideologies. ${ }^{17}$ Following the definition provided by North, we assume that ideologies enable individuals to make broad judgements regarding the environment in which they operate and about which individuals have, at best, incomplete factual knowledge. To capture this notion more specifically, we will let $\Psi$ represent the superset of knowledge.

\footnotetext{
${ }^{15}$ We elaborate on the determination of this aggregate as well as the creation of new technologies in Sections 3.3-3.5.

${ }^{16}$ This assumption allows us to pin down the interest rate at the discount rate. We do this to simplify the analysis. Neither relaxing this assumption nor allowing consumption in periods prior to the third would materially affect our results.

${ }^{17}$ In applying our model to the choice of ideology in a given economy, we do not restrict the set of ideologies available to individuals in that economy to be identical to those in other economies. The implication of this assumption is that all economies may not adopt the same ideologies. Although in our model the set of ideologies is determined exogenously, differences in the set of available ideologies may arise due to lack of information about alternatives or as a result of social or political forces at work in the economy.
} 
This set includes all knowledge relevant to the production environment. ${ }^{18}$ Education allows individuals to learn a subset of $\Psi$. Specifically, $\Psi$ is an ordered set with elements, $\psi, \psi \in[0, \bar{\psi}]$, where $\bar{\psi} \in(0, \infty)$. For simplicity, we assume that the elements of $\Psi$ can be learned sequentially in order of complexity. In particular, once an individual has knowledge of the element with order $\hat{\psi}, \hat{\psi} \in[0, \bar{\psi}]$, we assume that they have knowledge of all elements with order less than $\hat{\psi}$. Then, an individual's human capital, $h_{t+1}$, is the maximum comprehended element in $\Psi$. This maximum is determined by both formal education acquired when young and the ideological inferences when old. This formulation can be summarized as

$$
h_{t+1}=\bar{\psi} e\left(\phi_{t}, \psi_{t+1}^{k}\right)
$$

where $\phi_{t}, \phi_{t}>0$, denotes the underlying level of technological sophistication of the economy in period $t$, and $\psi_{t+1}^{k}$ is the maximum element in $\Psi$ correctly inferred through adherence to ideology $k, k \in[0, \kappa] .{ }^{19}{ }^{20}$ In (3), the function $e($.$) describes the pro-$ cess through which the sophistication of technology and ideology jointly determine the productivity of formal education. It is twice-differentiable, continuous and satisfies the following: $e\left(0, \psi_{t+1}^{k}\right) \geq 0, e\left(\infty, \psi_{t+1}^{k}\right)=1, e_{\phi}, e_{\psi}>0, e_{\phi \phi}, e_{\psi \psi} \leq 0$, and $e_{\phi \psi}, e_{\psi \phi} \geq 0$. Note that we do not assume $e\left(\phi_{t}, 0\right)=0$; i.e., individuals can still learn some of the elements of $\Psi$ through schooling even if they do not subscribe to an ideology. ${ }^{21}$ The process of learning defined above implies that $h_{t+1}$ is in the interval $[0, \bar{\psi}]$. Moreover, note that, $\forall \phi_{t}, \psi_{t+1}^{k} \geq 0$, when $e_{\psi}>0$, a person's ideology influences his/her learning, and that when $e_{\psi}=0$, the process of learning is independent of ideological inferences and interpretations.

\footnotetext{
${ }^{18} \Psi$ contains information about laws of nature as well as all socio-economic institutions and practices that may potentially affect productivity and that are not directly relevant to utility maximization. Thus, as will become clear later, we adopt the standard assumption that all individuals are able to evaluate the impact of different methods of human capital accumulation on wages.

${ }^{19}$ We describe how individuals make ideological inferences in more detail below.

${ }^{20}$ More realistically, we could have specified the technology of education as an increasing function of the amount of time individuals devote to education when they are young. However, given that in our setup there exists no alternative use of time in the first period of life, individuals would have chosen to devote all of their youth to education in that case as well, leaving the results presented below fully intact.

${ }^{21}$ Below we show that in equilibrium individuals would never adopt an ideology such that $\psi^{k}=0$. Thus, $\psi^{k}=0$ only if individuals choose not to adopt an ideology.
} 
In equation (3), higher values of $\psi_{t+1}^{k}$ imply that ideology $k$ allows a larger portion of $\Psi$ to be correctly inferred. Letting $I^{k}, I^{k}: R_{+} \rightarrow R_{+}$, represent a mapping from an individual's human capital $h_{t+1}$ to the knowledge superset $\Psi$ for ideology $k$, we assume that

$$
\psi_{t+1}^{k}=I^{k}\left(h_{t+1}\right),
$$

where $I^{k}(0)>0, I^{k}(\bar{\psi})=\psi_{\max }^{k} \leq \bar{\psi}, I_{h}^{k} \geq 0$, and $I_{h h}^{k} \leq 0$. Equation (4) suggests that a given level of human capital would generate different inferences about the knowledge superset $\Psi$ under different ideologies.

Taken together, equations (3) and (4) highlight how ideology and human capital interact with each other. Equation (3) shows how the efficiency of formal education is related to the choice of ideology; individuals who have adopted more fact-consistent ideologies will gain more knowledge through schooling. Equation (4) shows that knowledge gained through ideology depends on two factors. One, the chosen ideology, and two, knowledge accumulated through formal schooling. Because we allow $I_{h}^{k}>0$, we let individuals with different levels of education but the same ideology to make different inferences. Thus, knowledge gained through schooling and knowledge gained through choice of ideology are simultaneously determined.

Remark 1: (i) $\forall h_{t+1} \geq 0$, higher $I_{h}^{k}$, implies that the mapping $I^{k}($.$) is$ more "efficient" at that level of $h_{t+1}$ and that ideological inference $\psi_{t+1}^{k}$ is more accurate. (ii) Higher human capital elasticity of ideological inference, $I_{h}^{k}\left(h / I^{k}\right)$, implies that ideology $k$ is more "flexible."

Part (ii) of Remark 1 simply indicates that, if the ideological interpretations of two individuals with different levels of human capital but the same ideology are exactly the same, then this particular ideology is perfectly inflexible. We should point out that 
although we call an ideology "flexible" if it produces more accurate predictions with higher levels of human capital, the flexibility of ideologies is only a long-run concept. For a specific individual within our economy, once ideology $k$ is adopted, it generates a particular $\psi_{t+1}^{k}$. In other words, we do not allow ideologies to be "flexible" for specific individuals.

When individuals subscribe to an ideology, their efficiency units of labor supply in period $t+1, l_{t+1}$, depends on a combination of their human capital, $h_{t+1}$, and their chosen ideology with which they make broader inferences about their environment. Although both schooling and ideology allow individuals to learn facts about the world, the way those facts are learned can affect the application of them in the production environment. In other words, we do not impose that facts learned through schooling and facts learned through ideology are perfect substitutes in production. Let $h_{t+1}^{0}$ denote an individual's human capital when he subscribes to no ideology at all. Then, his "ideology-adjusted" efficiency units of labor, $l_{t+1}$, is given by the following:

$$
l_{t+1}= \begin{cases}l\left(h_{t+1}, \psi_{t+1}^{k}\right) & \text { if the individual subscribes to ideology } k \\ h_{t+1}^{0} \equiv \bar{\psi} e\left(\phi_{t}, 0\right) & \text { if the individual subscribes to no ideology }\end{cases}
$$

where the function $l($.$) is homogenous of degree one and satisfies the following: l\left(0, \psi_{t+1}^{k}\right)$ $=l\left(h_{t+1}, 0\right) \geq 0, l\left(\infty, \psi_{t+1}^{k}\right)=l\left(h_{t+1}, \infty\right) \leq \infty, l_{h}, l_{\psi}>0, l_{h h}, l_{\psi \psi} \leq 0$, and $l_{h \psi}, l_{\psi h} \geq$ 0.22

Remark 2: (i) When $\psi_{t+1}^{k}>h_{t+1}, l\left(h_{t+1}, \psi_{t+1}^{k}\right)=h_{t+1} l(1, a)>h_{t+1}^{0}$ where $a=\psi_{t+1}^{k} / h_{t+1}>1$; (ii) When $\psi_{t+1}^{k} \leq h_{t+1}, l\left(h_{t+1}, \psi_{t+1}^{k}\right)=h_{t+1} l(1, a) \gtreqless$ $h_{t+1}^{0}$, where $a=\psi_{t+1}^{k} / h_{t+1} \leq 1$.

Proof: Both (i) and (ii) follow directly from $l($.$) being homogenous of degree$ one, $e_{\psi}, l_{h}, l_{\psi}>0, l_{h h}, l_{\psi \psi} \leq 0$, and $l_{h \psi}, l_{\psi h} \geq 0$.

\footnotetext{
${ }^{22}$ Evidence in Sacerdote and Glaeser suggests that the cross partials, $l_{h \psi}$ and $l_{\psi h}$, may be zero. Nonetheless, to employ a more general specification, we do not restrict these cross partials to only that case.
} 
In words, part (i) of Remark 2 implies that, when an ideology $k$ provides additional knowledge above and beyond what is learned through schooling (so that $h_{t+1}>h_{t+1}^{0}$ ), it enhances the efficiency of labor supply. In addition, the more accurate and revealing ideological inferences, the larger is the impact of ideology on the supply of labor. Interestingly though, as part (ii) of Remark 2 indicates, even when an ideology is flawed in that $\psi_{t+1}^{k}<h_{t+1}^{0}$, it may still enhance the efficiency of labor. The reason for this is that ideological inference, $\psi_{t+1}^{k}$, affects the process of schooling and the accumulation of human capital, $h_{t+1}$. Moreover, despite the fact that schooling reveals more knowledge than what an ideology $k$ can offer when one subscribes to it, the stock of human capital is still higher than that when one does not subscribe to any ideology. Thus, in this sense, there exists circumstances under which a flawed ideology is better than no ideology.

Given that the utility function is linear in consumption in the last period, $c_{t+1}$, individuals choose an ideology $k$ in order to maximize $c_{t+1}$ subject to $c_{t+1} \leq w_{t+1}$. $l_{t+1}$, $k \in[0, \kappa]$, and equations (2)-(5). Thus, individuals choose to adopt an ideology $k, k \in$ $[0, \kappa]$, if and only if, $\forall d \neq k$,

$$
l\left(h_{t+1}, \psi_{t+1}^{k}\right) \geq l\left(h_{t+1}, \psi_{t+1}^{d}\right)
$$

and,

$$
l\left(h_{t+1}, \psi_{t+1}^{k}\right) \geq h_{t+1}^{0} .
$$

Equation (6) indicates that an individual subscribes to the ideology $k, k \in(0, \kappa]$, that maximizes his ideology-adjusted units of efficiency units of labor, $l_{t+1} \cdot{ }^{23}$ Equation (7) implies that the chosen ideology is such that, given the interpretation it provides, it helps positively augment the individual's human capital level, $h_{t+1}$. Otherwise, the

\footnotetext{
${ }^{23}$ Given that $\psi_{t+1}^{k}$ depends on the level of human capital and we allow ideologies to differ in their flexibility, it could be the case that the ideology that gives the highest $\psi$ changes as the level of human capital increases. We discuss this possibility more thoroughly in Section 4 when we discuss the dynamics of the economy.
} 
individual finds it optimal to subscribe to no ideology at all. ${ }^{24}$

Proposition 1: If ideologies are inflexible so that their human capital elasticity of ideological inference, $I_{h}^{k}\left(h / I^{k}\right)$, is less than unity, then $\exists \tilde{\phi}, 0 \leq \tilde{\phi} \leq$ $\infty$, such that, $\forall \phi_{t} \leq \tilde{\phi}$, individuals subscribe to ideology $k$, and $\forall \phi_{t}>\tilde{\phi}$, individuals subscribe to no ideology $k, k \in[0, \kappa]$.

Proof: If $\phi_{t}=\infty$, then $e\left(\infty, \psi_{\max }^{k}\right)=1 \Rightarrow h_{t+1}=\bar{\psi}$. Thus, $h_{t+1}=\bar{\psi} \geq \psi_{\max }^{k}$. If $\psi_{\max }^{k}=\bar{\psi}$, then $l\left(h_{t+1}, \psi_{t+1}^{k}\right)=\bar{\psi} l\left(1, \psi_{\max }^{k} / \bar{\psi}\right)=\bar{\psi}=h_{t+1}^{0}$, and individuals are indifferent to subscribing to ideology $k$ when $\phi_{t}=\infty$, in which case $\tilde{\phi}$ $=\infty$. If $\psi_{\max }^{k}<\bar{\psi}$, then when $\phi_{t}=\infty, l\left(h_{t+1}, \psi_{t+1}^{k}\right)=\bar{\psi} l\left(1, \psi_{\max }^{k} / \bar{\psi}\right)<\bar{\psi}$ $=h_{t+1}^{0}$, and individuals prefer to subscribe to no ideology. However, when $\phi_{t}=0, \psi_{t+1}^{k}=I^{k}(0)>0$ and $h_{t+1}=\bar{\psi} e\left[0, I^{k}(0)\right]=0$. Thus, given that $e(),. I^{k}($.$) and l($.$) are all continuous \exists \tilde{\phi}, 0<\tilde{\phi}<\infty$, such that $l\left(h_{t+1}\right.$, $\left.\psi_{t+1}^{k}\right)=\bar{\psi} e\left(\tilde{\phi}, \psi_{t+1}^{k}\right) l\left(1, \psi_{t+1}^{k} / \bar{\psi}\right)=\bar{\psi} e(\tilde{\phi}, 0)$. If the human capital elasticity of ideological inference is less than unity so that, $\forall h_{t+1} \geq 0, I_{h}^{k}\left(h / I^{k}\right)<1$, improvements in $\phi_{t}$ raise the human capital stock $h_{t+1}$ which in turn leads to a disproportionately smaller increase in ideological inference. From continuity of $e(),. I^{k}($.$) and l($.$) , it follows that \forall \phi \leq \tilde{\phi}$ individuals subscribe to ideology $k$, and $\forall \phi_{t}>\tilde{\phi}$, individuals subscribe to no ideology $k, k \in[0, \kappa]$.

Figures 1.a and 1.b depict two equilibria; one for $\phi_{t}<\tilde{\phi}$ and the other for $\phi_{t}>\tilde{\phi}$. Figure 1.a demonstrates that, when $\phi_{t}<\tilde{\phi}$, the stock of human capital is bounded from above at $\bar{\psi} e\left(\phi_{t}, \psi_{\max }^{k}\right)$, which is strictly less than $\psi_{\max }^{k}$. The latter, of course, is the upper bound of the support for ideological inference $I^{k}\left(h_{t+1}\right)$. Consequently, in equilibrium $\psi_{t+1}^{k}$ $=I^{k}\left(h_{t+1}\right)>\bar{\psi} e\left(\phi_{t}, \psi_{t+1}^{k}\right)=h_{t+1}$. Thus when the level of the technology is relatively

\footnotetext{
${ }^{24}$ There are historical examples in which one society forced its ideology onto others. Even today, there exist social costs of abandoning the ideology of family or those of the social group within which one operates. We could incorporate the latter into our model with some switching costs, and one of the ways the former can be captured is by including the odds of survival in the utility function. In a sense, those societies which accepted by force others' ideologies were maximizing their utility via ensuring survival. In either case, maximizing economic efficiency might not be paramount in the choice of ideology. However, our model would still be useful in understanding the consequences of adopting a less fact-consistent ideology: lower human capital and slower technological progress.
} 
low such that $\phi_{t}<\tilde{\phi}$, the benefits of education is relatively limited and subscribing to ideology $k$ strictly improves individuals' overall productivity and raises the efficiency of their labor supply. In contrast, Figure 1.b shows that, when the level of technology is more sophisticated so that $\phi_{t}>\tilde{\phi}$, the upper bound of the support for human capital, $\bar{\psi} e\left(\phi_{t}, \psi_{\max }^{k}\right)$, is much higher and has the potential to exceed the upper bound of the support for ideological inference $\psi_{\max }^{k}$. As a result, when technology is relatively advanced so that $\phi_{t}>\tilde{\phi}$, education is relatively more rewarding and subscribing to ideology $k$ does not improve individuals' overall productivity and their efficiency labor supply.

[Figures 1.a and 1.b about here.]

Note that, since all individuals are identical and the population is normalized to one, the aggregate units of ideology-adjusted efficiency labor, $L_{t+1}$, equals $l_{t+1}$. Let $h\left(\phi_{t} ; k\right) \equiv \bar{\psi} e\left(\phi_{t}, \psi_{t+1}^{k}\right)$ and $\iota\left(\phi_{t} ; k\right) \equiv l\left\{\bar{\psi} e\left(\phi_{t}, \psi_{t+1}^{k}\right), I^{k}\left[\bar{\psi} e\left(\phi_{t}, \psi_{t+1}^{k}\right)\right]\right\}$. Taken together with (3)-(5) and Proposition 1, this implies that

$$
L_{t+1}=l_{t+1}= \begin{cases}\iota\left(\phi_{t} ; k\right) & \text { if } \phi_{t} \leq \tilde{\phi} \\ h\left(\phi_{t} ; 0\right)>\iota\left(\phi_{t} ; k\right) & \text { if } \phi_{t}>\tilde{\phi}\end{cases}
$$

\subsection{The Technology}

In addition to the labor aggregate, $L_{t}$, machines are also an important part of the production process and, as we show in this section, their technological sophistication will ultimately depend on $L_{t}$. The formulation of the machinery aggregate which we describe below follows the standard specification employed in Acemoglu (1998). In this section we lay out a framework to establish: 1) The demand for machines and the profitability of R\&D in new technology increase with the level of technology embedded in the machines and in the level of the labor aggregate, $L_{t}$; and 2) The probability of new inventions increases with the expected profitability of R\&D. Taken together with the role of ideology in formulating the labor aggregate, these two relationships imply 
that more fact-consistent ideologies (those with higher $\psi_{t+1}^{k}$ 's) will be associated with a higher probability of technological advancement. ${ }^{25}$

More specifically, we assume that firms must purchase new machines in every period $t$ because machines depreciate fully in one period. Let $q_{t}$ denote the quantity of machines utilized in production at time $t$. The machinery aggregate used in production at time $t$, $M_{t}$, embodies both the quantity and the technological sophistication of machines:

$$
M_{t}=\frac{\phi_{t} q_{t}}{\alpha^{\frac{1}{\alpha}}}
$$

A new invention moves the underlying quality per machine one step up the quality ladder. In particular, when there is an invention, the technology level $\phi_{t}$ increases such that $\phi_{t}=\bar{g} \phi_{t-1}$, where $\bar{g}>1 .^{26}$

\subsection{The Adoption of New Technologies}

The decision of a firm $j, j \in[0,1]$, is

$$
\max _{\phi_{t}^{j}, q_{t}^{j}, L_{t}^{j}} \pi_{t}^{j}=\left(M_{t}^{j}\right)^{\alpha}\left(L_{t}^{j}\right)^{1-\alpha}-p_{t} q_{t}^{j}-w_{t} L_{t}^{j}
$$

where $p_{t}$ denotes the price per machine, which the firm takes as given. The solution to this problem yields, $\forall j \in[0,1]$,

$$
q_{t}^{j}=\left[\frac{\left(\phi_{t}^{j}\right)^{\alpha}\left(L_{t}^{j}\right)^{1-\alpha}}{p_{t}}\right]^{\frac{1}{1-\alpha}}
$$

\footnotetext{
${ }^{25}$ Clearly, all of the results developed so far would go through if we assumed that technological progress were exogenous. By endogenizing technological progress in this section, however, we are able to make the model richer by highlighting the role of ideology in creating incentives for R\&D via its effect on the efficiency units of labor in the economy.

${ }^{26}$ For simplicity, we have assumed that, whenever a discovery of a new technology is made, the leap up the ladder is by the same proportion. Under a more realistic setup in which the size of the jump or the number of jumps up the technology ladder in any one period is allowed to vary, the qualitative nature of the results presented below would be unchanged.
} 
As (11) implies, the demand for machines is strictly increasing in the level of the underlying technology, $\phi_{t}$. If at any given time $t$ machines embed a new quality improvement, a single firm will own the patent for them. For older vintages of technology, we assume that any prior patents have expired, the blueprints are readily available, and that any firm can produce machines that embed old technology at the constant marginal $\operatorname{cost} c .^{27}$

Given that older vintages of technology are always available at a lower price, there is no guarantee that firms will prefer to buy machines which incorporate the newest technology at a monopoly price. Firms will only be willing to pay a premium for new technology if the resulting increase in efficiency is large enough. Even when the net efficiency gains warrant final-goods producers to switch to the newest technology machines, however, the monopolist may not be able to charge $c / \alpha$, which is the unconstrained optimal monopoly price given the isoelastic demand for machines defined by (11). Hence, the monopolist's markup, $p_{t} / c$, would equal the smaller of $1 / \alpha$ and that which would make final goods producers indifferent between buying newer machines sold at monopoly markups.

\section{Lemma 1:}

$$
\frac{p_{t}}{c}=\min \left(\frac{1}{\alpha}, \bar{g} c\right)>1 .
$$

Proof: Final-goods producers utilize machines with the lowest quality adjusted price. They can acquire older vintage machines which embed technology $\phi_{t-1}$ at marginal cost $c$. They can buy machines with newest technology $\phi_{t}$ at the monopoly price $p_{t}$. Comparing $p_{t} / \phi_{t}$ with $c / \phi_{t-1}$ we find that finalgoods producers choose to buy machines with older technologies if $p_{t} \leq \bar{g} c$. This implies that $\left(p_{t} / c\right)=(1 / \alpha)$ if $\bar{g} c>(1 / \alpha)$, and $\left(p_{t} / c\right)=\bar{g}$ if $\bar{g} c \leq(1 / \alpha)$.

\footnotetext{
${ }^{27}$ We have chosen to maintain a constant marginal cost for machine production to keep the analysis focused on the relevant dynamics. If the cost of machine production was allowed to vary over time, increased sophistication of the technology would argue for an increasing cost but higher production efficiency could have a potentially offsetting effect.
} 
Note that, the monopoly price of machines that embed newly discovered technologies is non-decreasing in improvements in the technology level, $\phi_{t}$. Moreover, Lemma 1 implies that monopolists' profits are smaller when they cannot charge the unconstrained optimal monopoly markup, $1 / \alpha$.

Lemma 2: (i) $\frac{\partial \pi_{t}}{\partial p_{t}} \geq 0$; (ii) $\frac{\partial \pi_{t}}{\partial L_{t}}>0$.

Proof:

(i)

$$
\begin{gathered}
\frac{\partial \pi_{t}}{\partial p_{t}}=-\frac{\alpha}{1-\alpha} \frac{q_{t}}{p_{t}}\left(p_{t}-\frac{c}{\alpha}\right) \geq 0 . \\
\frac{\partial \pi_{t}}{\partial L_{t}}=\frac{\partial q_{t}}{\partial L_{t}}=\frac{q_{t}}{L_{t}}>0 .
\end{gathered}
$$

\subsection{Equilibrium R\&D Effort}

Improvements in the sophistication of technology are the result of $\mathrm{R} \& \mathrm{D}$ carried out by research firms which use the final consumption good as their only input. In any given period $t$, there exists a finite number of exogenously given $\mathrm{R} \& \mathrm{D}$ firms, $N$, who behave competitively. Let $\lambda_{t}$ denote the economy-wide probability that a new invention will actually occur in period $t$. We assume that this probability depends positively on aggregate resources spent on $\mathrm{R} \& \mathrm{D}$ :

$$
\lambda_{t}=\lambda\left(\omega_{t}\right)
$$

where $\omega_{t}$ is the aggregate resources spent on $\mathrm{R} \& \mathrm{D}$ in period $t$. The function $\lambda_{t}$ is such that $\lambda^{\prime}>0, \lambda^{\prime \prime} \leq 0, \lambda_{t}(0)=0, \lambda_{t}(\infty)=\bar{\lambda} \leq 1 .^{28}$

\footnotetext{
${ }^{28}$ In this specification, resources determine the probability of a change in the level of technology, independent of the prevailing ideology. In equilibrium, of course, ideologies that are less fact-consistent $\left(\right.$ lower $\psi_{t+1}^{k}$ ) will be associated with lower levels of technology overall.
} 
If aggregate $R \& D$ activity is successful in advancing the economy-wide level of technology in use, the probability that any given $R \& D$ firm lands the monopoly rights to sell new technology machines depends on the relative share of resources the firm spends on R\&D, $\omega_{t}^{n} / \omega_{t},(n=1,2,3, \ldots, N)$. Put differently, conditional on the fact that a technological improvement has occurred in any period $t$, the odds of a particular R\&D firm $n$ being the inventor of that new technology depend positively on its R\&D spending relative to total $R \& D$ expenditure, $\omega_{t}^{n} / \omega_{t}$.

Monopolists' patents expire after one period. Thus, if the technology does not become obsolete after one period, consumption-goods firms can replace existing machines at their marginal cost, c. (Because machines depreciate fully in one period, producers must purchase new machines in each period.) The decision of an R\&D firm, $n, n=$ $1,2,3, \ldots, N$, is

$$
\max _{\omega_{t}^{n}}\left(\lambda_{t} \pi_{t} \frac{\omega_{t}^{n}}{\omega_{t}}-B \omega_{t}^{n}\right),
$$

where $\lambda_{t} \pi_{t}\left(\omega_{t}^{n} / \omega_{t}\right)$ denotes the expected monopoly profits from a new invention, $B$, $B>0$, is the marginal cost of the R\&D effort in terms of the consumption good ${ }^{29}$, and where $\pi_{t}=\left(p_{t}-c\right) q_{t}=\left(p_{t}-c\right) \int_{0}^{1} q_{t}^{j} d j$.

Proposition 2: A solution to the problem specified above exists and, $\forall n=$ $1,2,3, \ldots, N$, one is given by

$$
\tilde{\omega}_{t}^{n}=\frac{\lambda_{t} \pi_{t}}{B N}
$$

where (17) implicitly defines $\tilde{\omega}_{t}^{n}$ as $\lambda_{t}=\lambda\left(N \tilde{\omega}_{t}^{n}\right)$.

\footnotetext{
${ }^{29}$ The main results of this paper are not dependent on the constant marginal cost assumption either. As in a number of other related papers, one could assume that the marginal cost of R\&D effort is a function of the sophistication of existing technology based on the notion that as the underlying technology improves, it gets more or less costly (in terms of the final consumption good) to improve it.
} 
Proof: See Appendix, Section 7.1.

Not surprisingly, aggregate equilibrium R\&D effort in inventive activity, $\tilde{\omega}_{t}, \tilde{\omega}_{t}=$ $N \tilde{\omega}_{t}^{n}$, is increasing in monopoly profits from that invention or innovation. ${ }^{30}$

Proposition 3: $\forall n=1,2,3, \ldots, N$,

$$
\left.\frac{\partial \tilde{\omega}_{t}^{n}}{\partial \pi_{t}}\right|_{\omega_{t}^{n}=\tilde{\omega}_{t}^{n}>0}
$$

Proof: See Appendix, Section 7.2.

\section{The Dynamics}

In this model, the dynamic evolution of the economy will be determined by the underlying level of technology, $\phi_{t}$, where

$$
\phi_{t}= \begin{cases}\bar{g} \phi_{t-1} & \text { with probability } \lambda_{t}, \\ \phi_{t-1} & \text { with probability } 1-\lambda_{t}\end{cases}
$$

\footnotetext{
${ }^{30} \mathrm{By}$ assumption, there is free-entry into research and development by relatively small firms. Those firms ignore their impact on both the economy-wide probability of success in generating new inventions and the total number of R\&D firms (which in turn affect the conditional odds of landing monopoly rights). If there had been one large firm engaged in $\mathrm{R} \& \mathrm{D}$, it would have taken into account the effect of changes in its R\&D resources, $\omega_{t}$, on the probability of invention, $\lambda_{t}$, but the qualitative nature of the results would have been unaffected. Similarly if there had been barriers to entry into the R\&D sector which would have restricted the number of firms engaged in research and development, we would have had to consider a game-theoretic solution but again the qualitative nature of the main results would have remained intact.
} 
Proposition 4: $\forall t \geq 0$, the set of available ideologies, $[0, \kappa]$, affects the evolution of the state variable $\phi_{t}$, which in turn determines the stochastic dynamic evolution of the economy.

Proof: Due to Remark 1 and the assumption $l_{\lambda}>0$, the more efficient the mapping $I^{k}($.$) , the higher is the efficiency units of labor, L_{t}$. Due to Lemma 2 , $\partial \pi_{t} / \partial L_{t}>0$. Given Proposition 3, $\left(\partial \tilde{\omega}_{t}^{n} / \partial \pi_{t}\right) \mid \omega_{t}^{n}=\tilde{\omega}_{t}^{n}>0$. Thus, $\forall h_{t} \geq 0$, the more accurate the mapping $I^{k}($.$) , the higher the probability of invention,$ $\lambda_{t}=\lambda\left(N \tilde{\omega}_{t}^{n}\right)$.

As the above proposition implies, the dynamics of the economy described above will be influenced to a significant extent by the initially available set of ideologies-and in particular, the efficiency with which these ideologies help individuals come to terms with the environment in which they conduct their economic activities. If there exists an ideology $k, k \in[0, \kappa]$, that provides its adherents relatively more accurate conjectures about facts which were not learned through formal human capital investment, it enhances the supply of efficiency labor in that economy. Because profits from invention are higher when workers are more productive, more fact-consistent ideologies will be associated with higher levels of R\&D investment and higher likelihood of even more inventions. Of course, the invention of more sophisticated technologies, in turn, stimulates further increases in R\&D, human capital investment, and faster growth. As we noted earlier in our introduction, however, because the current level of technology is also a determinant of the efficiency of education in learning the true facts about the world, more fact-consistent ideologies that initially produce higher levels of technology may also become obsolete. In other words, as technological progress makes education more efficient in learning about the world, an unchanging ideology may eventually be abandoned. ${ }^{31}$ Whether that ideology is abandoned for another ideology or for no ideology at all depends on whether alternative ideologies provide more accurate inferences (higher $\psi_{t+1}^{k}$ ) at the higher level

\footnotetext{
${ }^{31}$ In fact, there seems to exist ample evidence in support of this view. For example, North states (1981, p. 169) "Both the political and the economic changes described above created impersonal factor and product markets and broke down old ideological loyalties...The Ind ustrial Revolution was characterized by sustained efforts to develop new social and ethical norms."
} 
of human capital. ${ }^{32}$

Not surprisingly, the long-term survival of an ideology depends on not only whether it enables its subscribers to reach inferences that are relatively more consistent with existing factual knowledge, but also whether it is flexible enough over time that its subscribers' inferences do not become highly at odds with the increasing stock of knowledge. When ideologies are relatively flexible so that its adherents' ideological inferences respond to changes in prevailing scientific knowledge, they will survive in the long run. In turn, they will inevitably lead to sustained technological progress.

Proposition 5: The more flexible a prevailing ideology $k, k \in[0, \kappa]$, the higher is $\tilde{\phi}, 0 \leq \tilde{\phi} \leq \infty$, such that, $\forall \phi_{t} \leq \tilde{\phi}$, individuals subscribe to ideology $k$, and $\forall \phi_{t}>\tilde{\phi}$, individuals subscribe to no ideology $k, k \in[0, \kappa]$.

Proof: As shown in Proposition $1, \exists \tilde{\phi}, 0 \leq \tilde{\phi} \leq \infty$, such that individuals are indifferent between subscribing to ideology $k$ and not subscribing to any ideology, and it is given by $l\left(h_{t+1}, \psi_{t+1}^{k}\right)=\bar{\psi} e\left(\tilde{\phi}, \psi_{t+1}^{k}\right) l\left(1, \psi_{t+1}^{k} / \bar{\psi}\right)=\bar{\psi} e(\tilde{\phi}$, 0 ). As defined in part (ii) of Remark 1, flexible ideologies have higher human capital elasticity of ideological inference, $I_{h}^{k}\left(h / I^{k}\right)$. Since $l_{\psi}>0$, it follows that, $\forall h_{t} \geq 0$, the higher is $I_{h}^{k}\left(h / I^{k}\right)$, the higher the threshold level of technology for which individuals are indifferent between subscribing to ideology $k$ and not subscribing to any ideology, $\tilde{\phi}$.

To elaborate further, take two ideologies that are relatively fact-consistent but that differ in their flexibility. Both will lead to more efficient labor and, as a result, faster technological progress. The difference is that the inflexible ideology provides its adherents inferences that are relatively similar for different levels of human capital. Education becomes more fruitful with improvements in the level of technology in the sense that a

\footnotetext{
${ }^{32}$ To illustrate an example of the switch from one ideology to another let $I^{k}=\left(h_{t+1}\right)^{a}$ and $I^{d}=$ $\left(h_{t+1}\right)^{b}$ where $a<b$ for some $d \neq k$. In this case, ideology d provides inferior inferences when $h_{t+1}$ is low but superior inferences when $h_{t+1}$ is high. In particular, there exists $\tilde{h}>0$ such that, $\psi_{t+1}^{k}>\psi_{t+1}^{d}$ when $h_{t+1}<\tilde{h}$ and $\psi_{t+1}^{k}<\psi_{t+1}^{d}$ when $h_{t+1}>\tilde{h}$.
} 
higher fraction of the knowledge superset can be revealed through formal learning when technologies are relatively more sophisticated. Consequently, as technological progress makes education more efficient in learning about the world, the economic benefits of subscribing to an inflexible ideology decline more quickly with improvements in technology. As a result, such an ideology will be abandoned sooner compared with a more flexible ideology. The latter, of course, allows its adherents to reach inferences that capture a greater fraction of the knowledge superset as their human capital expands in response to improvements in the technology level. Thus, it remains economically useful for a longer period of time.

[Figure 2 about here.]

\section{Implications and Further Discussion}

The model laid out above has a number of specific implications, some of which we have already discussed. In this section, we highlight the major ones more formally and present the supporting evidence that are relevant to each.

I) Technological advances will lead to lower (higher) support for ideologies that impede (enable) their followers from adjusting their ideological inferences accordingly.

As we stated in our introduction, Comte and Hume originally promoted the strictest form of the idea that scientific knowledge dispels religious beliefs. Since our model allows ideologies to differ in their flexibility of interpretation, its relevant implication is subtler: The popularity and the following of the more fervent ideologies would decline in the face of improvements in technological sophistication. In fact, as Sacerdote and Glaeser show, more educated individuals sort into less dogmatic religious denominations. They note that most of these less fervent denominations provide their followers more flexibility, for example, in interpreting the connections among religiosity, worldly success and spiritual rewards after death.

II) Inflexibilities in ideological interpretations will lead to depressed worker productivity, slower economic growth and development. 
Many historians have stressed the importance of a society's culture, ideology or religion in its willingness to adopt foreign ideas or technologies. ${ }^{33}$ For instance, Europeans embraced gadgets like the compass and the cannon that were invented during the 14th -century technological breakthrough epoch in China. The fact that the Chinese were not as receptive and resisted adopting most of the inventions of the Industrial Revolution contributed, at least in part, to the wide gap between the existing standards of living in Europe and China today. In a similar vein, the decline and demise of the Ottoman Empire, which began in the 17th century, is attributed to the Islamic world's resistance to foreign ideas-and in particular, to the outright rejection of the printing press. ${ }^{34}$ III) Ideological reforms could potentially lead to technological breakthroughs and rapid improvements in the standard of living.

Despite the fact that we do not explicitly model a process of ideological reform, our model implies that the emergence of a new ideology (or interpretation) would lead to an epoch of technological change and a corresponding increase in the standard of living. As is well known, important ideological reforms preceded the Industrial Revolution. The Renaissance led to the transformation of ideological values and interpretations in Europe, due in part to the willingness of contemporary theologians to accept Humanist teachings that were rejected and suppressed during earlier periods. ${ }^{35}$ Moreover, there exists a vast literature-and somewhat of a consensus-on the link between the Protestant reform movement led by John Calvin in the early-16th century and the Industrial Revolution that followed about one hundred and fifty years later. ${ }^{36}$

IV) Periods of rapid technological change may induce revisions in existing ideological norms and practices.

As summarized in Remark 1, we allow for ideological interpretations to be influenced by the human capital level of individuals who subscribe to them (i.e., for ideologies to differ in their flexibility of interpretation). In addition, in our setup, knowledge (or human capital) accumulation speeds up during periods of rapid technological change. This suggests that epochs of invention may lend themselves to the emergence of new ideological

\footnotetext{
${ }^{33}$ See, for example, Mokyr (1990) and Landes (1998, 2000).

${ }^{34}$ Weil (forthcoming).

${ }^{35}$ See Hale (1993).

${ }^{36}$ Rosenberg and Birdzell (1986).
} 
norms and practices. In fact, as North (pp. 169-170) observes, the Industrial Revolution "created impersonal factor and product markets and broke down old ideological loyalties...[It] was characterized by sustained efforts to develop new social and ethical norms."

$V)$ Widespread adoption of new ideologies is more frequent the less sophisticated the technology.

As Proposition 5 suggests, another implication of our model is that the process of economic development will narrow down the feasible set of ideologies over time. The reason is that the subset of productivity-enhancing ideologies in the continuum $[0, \kappa]$ gets smaller as the technology parameter $\phi_{t}$ improves due to new inventions. ${ }^{37}$ Analogously, the set of feasible, productivity-enhancing ideologies may be larger when time devoted to formal schooling is not particularly rewarding-as would be the case when existing technologies are rather primitive. When that is the case, of course, it is more likely that any given ideology $k, k \in[0, \kappa]$, is productivity enhancing despite the inherent inconsistencies of this particular ideology with facts that are yet to be revealed.

\section{Conclusion}

Ideologies serve a purpose. They allow generalizations about the complex environment within which individuals operate when knowledge is incomplete. From this perspective, it seems imperative to analyze the dynamics of human capital accumulationand how these dynamics might be related to technological change-in conjunction with individuals' ideological choices and interpretations.

In the model presented in this paper, we focus on this interplay during the process of development. We construct an endogenous growth model in which technological progress raises the efficiency of time allocated to education and in which knowledge and ideology play complementary roles in determining individuals' efficiency units of labor supply. Education allows individuals to learn more about their environment, and ideology helps them to adopt a broader view of the latter about which they acquire incomplete information via education.

Our results demonstrate how ideologies that are more consistent with reality are

\footnotetext{
${ }^{37}$ Note that, as Equation (7) implies, this set includes $\forall k, k \in[0, \kappa]$, such that $l\left(h_{t+1}, \psi_{t+1}^{k}\right) \geq h_{t+1}^{0}$.
} 
likely to foster human capital accumulation, technological progress and economic growth. Somewhat paradoxically, we also show that relatively more fact-consistent ideologies are the ones likely to experience a weakening support in the long run. In our model we emphasize an important two-way interaction between education and ideology. This interaction plays a crucial role in determining whether ideologies are flexible enough to survive in the long run. Based on the interaction between education and ideology, we show that there exists circumstances in which a flawed ideology is better than no ideology. And finally, our model suggests that the frequency with which ideologies are adopted and spread is decreasing in the sophistication of technology.

In sum, we unify existing work that shows the mutual dependence of choices regarding ideology and human capital with that on the link between human capital and long-run economic performance. In doing so, we underline the importance of ideologies in leading to differential growth and development patterns across countries over time. 


\section{Appendix}

- 7.1. Proof of Proposition 2:

For each firm, $n, n=1,2,3, \ldots N$, which takes as given the aggregate amount of resources devoted to $R \& D$ in inventive activities, $\omega_{t}$, the following hold:

$$
\omega_{t} \begin{cases}=0 & \text { if } \lambda_{t} \pi_{t}<B \omega_{t} \\ \in(0, \infty) & \text { if } \lambda_{t} \pi_{t}=B \omega_{t} \\ =1 & \text { if } \lambda_{t} \pi_{t}>B \omega_{t}\end{cases}
$$

Given that all R\&D firms are identical, $\omega_{t}=0$ and $\omega_{t}=1$ cannot hold in equilibrium, and $\omega_{t} \in(0, \infty)$ has to hold. And $\omega_{t}=N \omega_{t}^{n}, \omega_{t} \in(0, \infty)$, is a non-trivial equilibrium outcome.

- 7.2. Proof of Proposition 3:

Using (17) and invoking the implicit function theorem,

$$
\left.\frac{\partial \omega_{t}^{n}}{\partial \pi_{t}}\right|_{\omega_{t}^{n}=\omega_{t}^{n}}=\frac{1}{N} \frac{\lambda_{t}}{B-\lambda^{\prime} \pi_{t}}
$$

In equilibrium resources devoted to $\mathrm{R} \& \mathrm{D}$ are such that $\lambda_{t} \pi_{t}-B \omega_{t}=0$. This, together with $\lambda^{\prime}>0, \lambda^{\prime \prime} \leq 0$, suggests that $B-\lambda^{\prime} \pi_{t}$ is strictly positive. Thus, (7.2) is strictly positive. 


\section{References}

Acemoglu, D. (1998). "Why Do New Technologies Complement Skills? Directed Technical Change and Wage Inequality," Quarterly Journal of Economics, 113(4), 1055-89.

Acemoglu, D., S. Johnson, and J. Robinson. (2000). "The Colonial Origins of Comparative Development: An Empirical Investigation," MIT, unpublished manuscript.

Anderson, G. M. (1988). "Mr. Smith and the Preachers: The Economics of Religion in the Wealth of Nations," Journal of Political Economy, 96(5), 1066-1088.

Azzi, C. and R. Ehrenberg. (1975). "Household Allocation of Time and Church Attendance," Journal of Political Economy, 83(1), February, 27-56.

Becker, G. and G. J. Stigler. (1977). "De Gustibus Non Est Disputanum," American Economic Review, 67, 2, 76-90.

Barnouw, J. (1981). "The Separation of Reason and Faith in Bacon and Hobbs, and Leibniz's Theodicy" Journal of the History of Ideas, 42, 607-28.

Carlton, E. (1977). Ideology and Social Order, (London: Routledge \& Kegan Paul).

Comte, A. (1974). The Positive Philosophy, (New York: A. M. S. Press), reprint of the 1855 translation of Cours de Philosophie Positive, (New York, C. Blanchard).

Cozzi, G. (1998). "Culture as a Bubble," Journal of Political Economy, 106 (2), April, 376-94.

Davies, P. (1983). God and the New Physics. (New York: Simon and Schuster).

Fershtman, C. and Y. Weiss. (1993). "Social Status, Culture and Economic Performance," Economic Journal, 103(419), 946-959.

Foster, M. B. (1934). "The Christian Doctrine of Creation and the Rise of Modern Natural Science," Mind, 43(172), 446-468.

Galor, O. and O. Moav. (1999). "From Physical to Human Capital Accumulation: Inequality in the Process of Development," Brown University Working Paper No: 199927 , July. 
Galor, O. and O. Moav. (2000a). "Ability Biased Technological Transition, Wage Inequality, and Economic Growth," Quarterly Journal of Economics, 115, May, 469-98.

Galor, O. and O. Moav. (2000b). "Natural Selection and the Origin of economic Growth," Brown University Working Paper No: 2000-18, September.

Galor. O. and D. N. Weil. (2000). "Population, Technology and Growth: From the Malthusian Regime to the Demographic Transition," American Economic Review, 90 (4), September, 806-28.

Hale, J. (1993). The Civilization of Europe in the Renaissance. (New York: Simon and Schuster).

Hall, R. E. and C. I. Jones. (1999). "Why Do Some Countries Produce So Much More Output Per Worker Than Others?," Quarterly Journal of Economics, 114, February, 83-116.

Hume, D. (1911). A Treatise of Human Nature, (London: J. M. Dent and Sons Ltd.).

Iannaccone, L. R. (1998). "Introduction to the Economics of Religion," Journal of Economic Literature, 36(3), September, 1465-95.

Jones, C. I. (1999). "Was an Industrial Revolution Inevitable? Economic Growth over the Very Long Run," NBER Working Paper No: 7375, October.

Knack, S. and P. Keefer. (1997). "Does Social Capital Have an Economic Payoff? A Cross-Country Investigation," Quarterly Journal of Economics, 112, November, 1251-88.

Kremer, M. (1993). "Population Growth and Technological Change: 1 Million B.C. to 1990," Quarterly Journal of Economics, 108(3), 681-716.

Landes, D. S. (1998). The Wealth and Poverty of Nations: Why Some are Rich and Some So Poor, (New York: W. W. Norton).

Landes, D. S. (2000). "Culture Makes Almost All the Difference," in Culture Matters: How Values Shape Human Progress, L. E. Harrison and S. P. Huntington (eds.), (New York: Basic Books).

Mokyr, J. (1990). The Lever of Riches, (New York: Oxford University Press). 
North, D. (1981). Structure and Change in Economic History, (New York: W. W. Norton and Company, Inc.).

Osler, M. J. (1970). "Locke and the Changing Ideal of Scientific Knowledge" Journal of the History of Ideas, 31, 3-16.

Romer, P. (1990). "Endogenous Technological Change," Journal of Political Economy, 98, October, S71-S102.

Rosenberg, N. and L. E. Birdzell, Jr. (1986). How the West Grew Rich. (New York: Basic Books).

Schumpeter, J. A. (1949). "Science and Ideology," American Economic Review, 39, $2,345-59$.

Sacerdote, B. and E. L. Glaeser. (2001). "Education and Religion," NBER Working Paper No: 8080, January.

Stark. R., L. R. Iannaccone, and R. Finke. (1996). "Religion, Science, and Rationality," American Economic Review, 1996 Papers and Proceedings, 86, 2, 433-37.

Stephen, L. (1876). English Thought in the 18th Century, (New York: Harcourt, Brace, and World, Inc.)

Weber, M. (1930). Protestant Ethic and the Spirit of Capitalism, trans. T. Parsons. (New York: Scribner \& Sons).

Weil, D. N. (forthcoming). Economic Growth.

Young, A. (1991). "Learning By Doing and the Dynamic Effects of International Trade," Quarterly Journal of Economics, 106(2), 369-405.

Young, A. (1993). "Invention and Bounded Learning By Doing," Journal of Political Economy, 101(3), 443-72. 


\section{Figure 1.a}

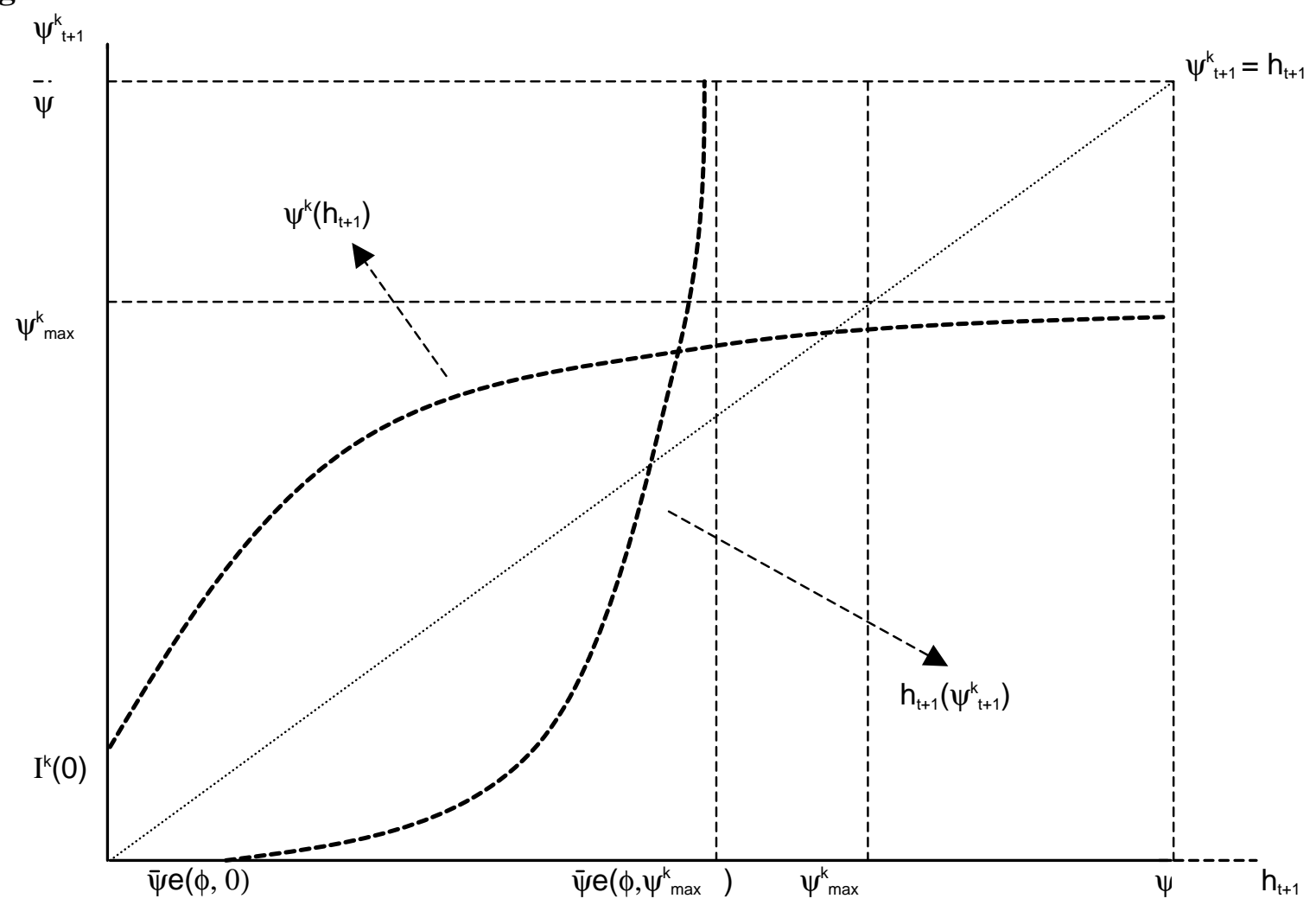

\section{Figure 1.b}

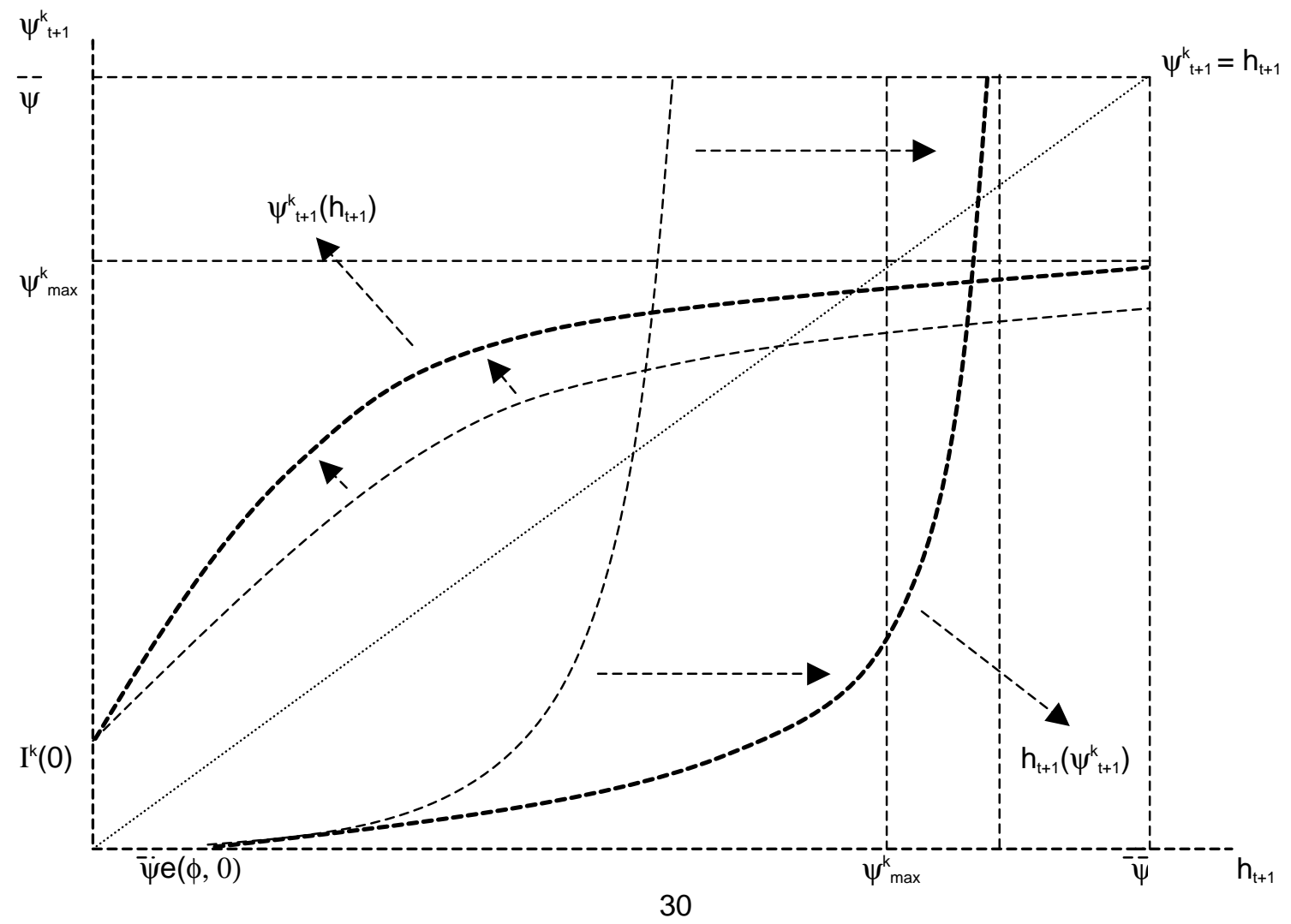


Figure 2:

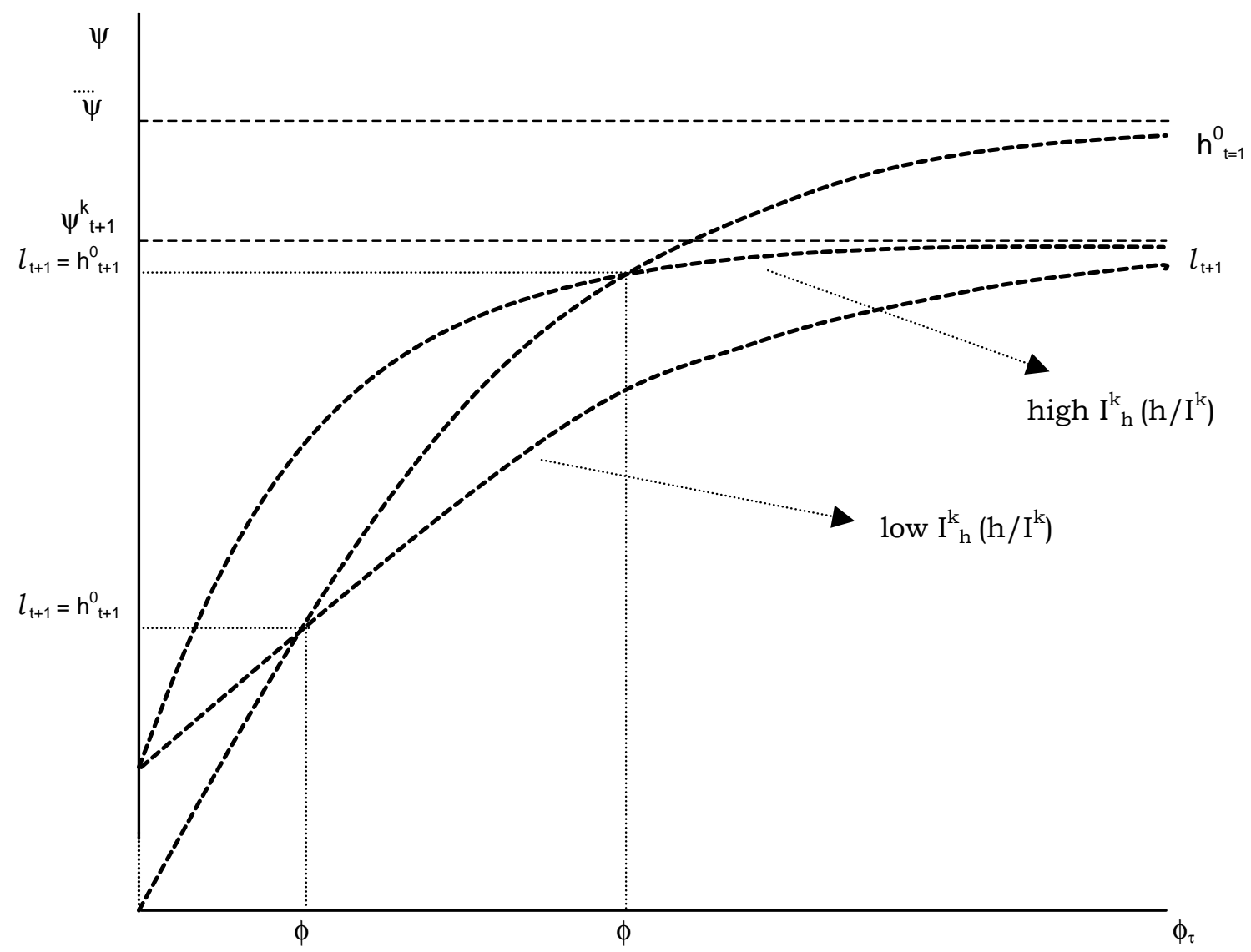

